\title{
Exploratory Research on Curriculum Construction of Medical Metrology Education in Colleges and Universities
}

\author{
Ze-Dong Yan, Wei Guo, Juan Liu, Er-Ping Luo, and Chi Tang
}

\begin{abstract}
Canonical and systematic quality-oriented education of medical metrology for undergraduate students has not been started in colleges and universities. The standardized training and professional cultivation system are also deficient for most medical metrological employees at present. In this study, special funds were invested to develop the teaching laboratory based on the establishment standards of national medical metrology stations. Experienced experts were also invited for the argumentation of curriculum construction and optimization of medical metrology. As a result, two undergraduate courses of medical metrology for the students majoring in Biomedical Engineering (BME) were developed for the first time based on the talent cultivation mode "basic knowledge + practical ability". An internationally-advanced teaching laboratory for medical metrology was established, and the series textbooks were compiled and published. It is of vital significance to strengthen the curriculum construction of medical metrology for undergraduate students of BME, which may provide beneficial reference for further medical metrological talent cultivation.
\end{abstract}

Index Terms-Medical metrology, biomedical engineering, curricula construction, cultivating mode.

\section{INTRODUCTION}

High-tech medical equipment has been emerging continuously with the rapid growth of international technology. As people enjoys the benefits of technological development and medicine improvement, the medical negligence and dispute have been increasingly prominent induced by adverse events related to medical devices [1], [2]. Therefore, it is of vital importance in the world medical health field to guarantee the reliable performance of armamentarium, decrease the clinical risks and ensure medical quality safety. The medical metrology is exactly the most effective method of solving the problems.

Medical metrology is an activity of guaranteeing the unit unity, magnitude accuracy and performance reliability in the measure of medical facilities. Medical metrology is an extended science of metrology in the medicine domain, which plays an important role in assuring the security of medical quality, reducing the adverse armaria-related events and improving the diagnosis and therapy efficiency [3]. Medical metrology belongs to legal management, which requires employees to receive related training and obtain professional qualifications before employed with certificates.

Manuscript received April 2, 2020; revised July 14, 2020.

Z.-D. Yan, W. Guo, J. Liu, C. Tang (corresponding author), and E.-P. Luo (corresponding author) are with the Department of Biomedical Engineering, Air Force Medical University, Xi'an 710032, China (e-mail: 358404030@163.com, guoweiguowen@163.com, liujuan@fmmu.edu.cn, tangchi@fmmu.edu.cn, luoerping@fmmu.edu.cn).
Nevertheless, investigations and surveys have showed that the undergraduate education of medical metrology has not yet been started in the colleges and universities. Most employees of medical metrology got their qualification only by a short-term training. The present nonstandard and unprofessional cultivation system of the medical metrological talents has resulted in the disorder of learning resources, the lack of systematical standardized training and the scarcity of high-level professionals, which may induce poor adaptability to the rapid development of science and technology and medical equipment [4].

Colleges and universities are the cradle of talents cultivation. The advantages of colleges and universities must be given full play to intensify their position and function in the cultivation of medial metrological talents. However, studies have indicated that there was only a medical metrology-related course for the doctoral students in Slovak University of Science and Technology. The undergraduate curricula related to the medical metrology have not yet established in domestic and overseas higher education institutions except the Air Force Medical University of PLA. The canonical and systematic quality-oriented education of medical metrological capability at colleges and universities (especially the undergraduate curricula construction) has been at flaw condition, which needs to be urgently strengthened [5], [6].

\section{Establishing Medical Metrology CURriculum IN THE MAJOR OF BME}

\section{A. Demand Analysis of the Talents' Knowledge Structure of Medical Metrology}

The medical metrology belongs to a burgeoning interdisciplinary discipline, which contains nearly ten fields of conventional medical domain (e.g. mechanology, thermology, electromagnetism, chemistry, etc.). The medical metering technology is currently developing towards digitization, intelligentization, real-timization and dynamical multi-parameterization with the widely application of advanced technology in medicine. Consequently, the talents of medical metrology in contemporary society are not only supposed to be equipped with fundamental knowledge of mathematics (statistics and error analysis), medical physics, medical chemistry, bioelectronics, cybernation, measuring technique, medical equipment, etc., but also the practical calibration ability, laws and regulations awareness and professional quality. The detailed structure of knowledge and specialty literacy are listed as follows.

1) Mathematical knowledge: the principles and methods of processing the measured results via medical statistics, 
theories of errors and uncertainty evaluation;

2) Professional basic knowledge: theories of medical physics, medical chemistry, physiology, biomedical electronics, auto-control, etc.;

3) Professional knowledge: theories of instruments and apparatus measuring technique, medical equipment, biomedical sensors, medical imaging, etc.;

4) Practical abilities: methods and professional requirements of medical metrology (e.g. sphygmomanometer, electrocardiograph, respirator, defibrillator, medical electrical security, etc.);

5) Laws and regulations knowledge: laws and regulations related to medical metrology, national metrological verification regulations (JJG) / national metrological calibration specifications (JJF) and national standard (GB) in medicine, preparation of medical metrology documents, criterion and guidelines of writing reports, etc.;

6) Professional qualities: honesty, incorruptibility, integrity, self-discipline, responsibility, dedication, abilities to communication and coordination, capacities for self-directed learning and teamwork.

\section{B. Talents in Biomedical Engineering: Main Force of Medical Metrology}

Biomedical Engineering (BME) is a newly-emerging interdiscipline aiming at solving the medical problems by synthetically utilizing the theories and methods of mathematics, physic, chemistry, computer and engineering science [7], [8]. The relation between BME and medical metrology can be viewed from the following three perspectives.

1) Discipline definition. Both BME and medical metrology (with high correlation) are interdisciplines belonging to the application of engineering in medicine. BME, as one of the first-class disciplines in all academic classifications, theoretically covers the category of medical metrology.

2) Talents' knowledge structure cultivation. Highly-related structure of the professional knowledge is required between $\mathrm{BME}$ and medical metrology on the cultivation of talents. The curriculum system of BME covers almost all professional knowledge mentioned above, especially the incomparable background knowledge of medicine throughout the whole process of teaching, which is critically demanded for the talents' knowledge structure of medical metrology. As a result, BME has the innate advantages in developing the education and work of medical metrology.

3) Talent cultivation objective. The objective of talent cultivation of BME locates in cultivating advanced engineering technician and scientific manpower to study, develop and administrate the medical equipment in the fields of BME and other related branches of industry [9]. The employment channels are generally divided into two major categories, i.e. the development and generalization of medical equipment, and the quality controlling, maintaining and management of medical equipment. Both categories require the supporting of the professional knowledge and techniques of medical metrology.

In conclusion, BME is highly correlated with medical metrology with highly intersected discipline contents and mutual supported disciplinary efficacy. It is supposed to be the main channel of cultivating the talent team of medical metrology to enhance medical metrological education in the major of BME in contemporary colleges and universities without relevant specialty at the undergraduate level. Consequently, the advantages of talent cultivation in colleges and universities must be taken to establish relevant curriculum of medical metrology for undergraduates during the college periods. The knowledge structure and practical abilities of students in the major of BME should be energetically cultivated to provide highly-competent talents for the sustainable development of medical metrology.

\section{EXPlORING THE MEdiCAL MEtRology CURRICUlum CONSTRUCTION}

Based on intensive argumentation for the urgent necessity of medical metrology talents cultivation, the corresponding curriculum of the medical metrology was firstly established for the undergraduate students in the major of BME in the Air Force Medical University of CPLA in 2016. With the goal of promoting the medical metrological capability of students majoring in BME in colleges and universities, the curriculum was systematically constructed in course provision, content designing, teaching model and evaluation methods based on the competency certification standards for medical metrologists, aiming at building a high-standard and normalized curriculum system of medical metrology with the "basic knowledge + practical ability" mode. Meanwhile, a new mode of the combination of course education and competency certification of medical metrology was also explored to promote the competence of students engaging in the relevant occupation, and also provide guidance and instruction for colleges and universities to develop preferable talents cultivation of medical metrology.

\section{A. Cultivating Mode}

Medical metrology is a discipline requiring solid professional qualities and data processing abilities, and also the practical capabilities to figure out problems in actual detection. Therefore, based on sufficient investigation and argumentation, a new talent cultivation mode of "basic knowledge + practical ability" was proposed and established aiming at the development situation and professional competence requirements of the medical metrology with the guidance of national competency certification standard of medical metrology. The cultivation of theoretical and practical capabilities was attached equal importance in teaching [10]. And the connection of theory and practice knowledge was specially emphasized to cultivate the ability of students to solve practical problems by utilizing medical metrological knowledge, which was applied for the guidance of curriculum construction and capability examination.

\section{B. Construction of Teaching Laboratory}

Aiming at the absence of experimental teaching conditions, the special funds of teaching facilities construction were invested from 2015 to purchase advanced medical metrological detection equipment based on the project of disciplinary conditional construction and the establishment standards of national third-class medical metrology stations and some first-class stations. The internationally-advanced 
teaching laboratory for medical metrology was then demonstrated and established covering 3 workstations (i.e. fundamental physical parameters, electrophysiological and irradiative units) and 14 metrological verification stations, including mass, temperature, pressure, airflow, electrosurgery, ultrasound, irradiation, etc. as shown in Fig. 1. The teaching laboratory has already equipped with sufficient hardware to independently develop practical teaching of medical metrology with up to 20 subjects. Considering that the medical metrological positions of students are mainly available to hospitals after their graduation, the three workstations (i.e. mass, temperature and pressure) were established by referring to the building standards of national tertiary (and some first-class) medical metrology stations to develop higher-level experimental teaching subjects of traceability and calibration. The establishment of the laboratory has dramatically improved the experimental teaching conditions and significantly enhanced the practical capabilities of students.

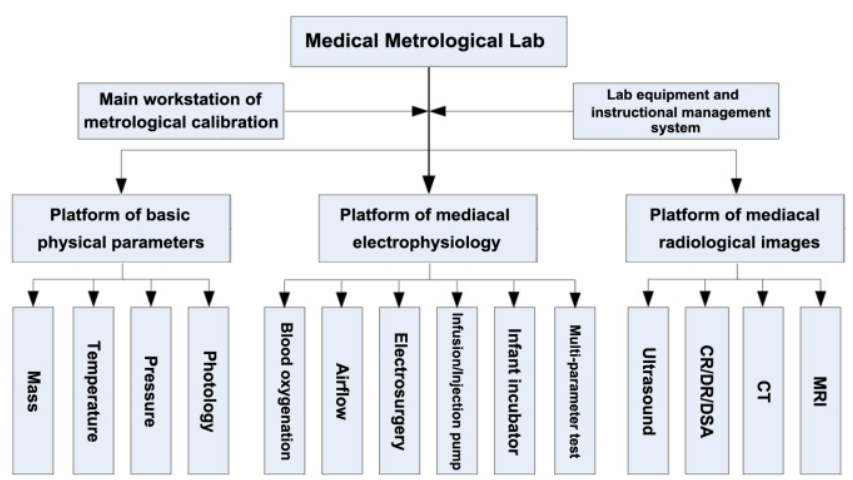

Fig. 1. The general structure of medical metrological laboratory.

\section{Construction of Teaching Textbooks}

Textbooks are knowledge carriers reflecting the course content and methods of instruction which are of great significance in improving teaching quality and achieving training objective and are playing an important fundamental role in the talent cultivation. At present, the talent cultivation of medical metrology was relied mainly on the short-term training and the corresponding undergraduate education has not yet been started in the colleges and universities. Therefore, there is an absence of serialized, systematized and normalized training materials in national medical metrology education, and the establishment of medical metrological textbooks are still spurious.

The development of our series textbooks of medical metrology training was started in 2013 by collaborating with National Medical Metrology Center. Fifteen experienced experts and professors on the forefront of medical metrology were invited for the textbooks compilation according to their own professional expertise. After repeated argumentation based on the knowledge structure and capacity requirements of medical metrological technician for three years, the series textbooks of medical metrology (i.e. basic knowledge of medical metrology, standards of calibration and experimental teaching, respectively) were projected, compiled and published. The development of the series textbooks was combined with the cultivation goals of "basic knowledge + practical ability", which has provided important supporting for the further standardized education of medical metrology in colleges and institutions.

Firstly, the fundamental theory consisting of 5 chapters were introduced in Medical Metrology, including basic knowledge of quantity and unit, uncertainty of measurement, law and regularity systems of medical metrology, and conformity assessment and laboratory accreditation. Then, the rationale of medical equipment and the methodology of metrological verification and calibration were also presented in Detection and Calibration of Medical Metrology, which contains 10 chapters including the medical mechanical, thermal, electrophysiological, ultrasonic, acoustic, optical, laser, biochemical and radiological metrology. Additionally, the specific technological processes of metrological verification and quality detection of 8 regular-inspected medical instruments, coupled with the processing methods of detected data, were introduced in Experimental Framework of Medical Metrology. The three textbooks are systematical training materials by combining the medical metrological theory with relevant practice, which can provide important supporting for the normalized education and teaching of medical metrology.

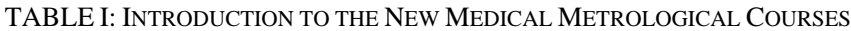

\begin{tabular}{|c|c|c|}
\hline Course & Medical Metrology & $\begin{array}{c}\text { Detection and Calibration of } \\
\text { Medical Metrology }\end{array}$ \\
\hline $\begin{array}{l}\text { Teaching } \\
\text { purpose }\end{array}$ & $\begin{array}{c}\text { Establishing basic } \\
\text { knowledge hierarchy } \\
\text { of medical metrology }\end{array}$ & $\begin{array}{l}\text { Cultivating practical skills } \\
\text { of each subject of medical } \\
\text { metrology }\end{array}$ \\
\hline Main content & $\begin{array}{l}\text { Basic knowledge, } \\
\text { development, laws } \\
\text { and regulations }\end{array}$ & $\begin{array}{l}\text { Calibration techniques of } \\
\text { common medical } \\
\text { instruments }\end{array}$ \\
\hline Textbook(s) & Medical Metrology & $\begin{array}{l}\text { Detection and Calibration of } \\
\text { Medical Metrology; } \\
\text { Experimental Framework of } \\
\text { Medical Metrology }\end{array}$ \\
\hline Teaching hours & 20 & 60 \\
\hline $\begin{array}{l}\text { Teaching } \\
\text { methods }\end{array}$ & Theory & Theory + Experiment \\
\hline $\begin{array}{l}\text { Evaluation } \\
\text { method }\end{array}$ & Theory examination & $\begin{array}{l}\text { Practical operation } \\
\text { examination }\end{array}$ \\
\hline $\begin{array}{l}\text { Ability } \\
\text { certification }\end{array}$ & \multicolumn{2}{|c|}{$\begin{array}{c}\text { Certificate of competency was awarded based on two } \\
\text { courses' grades }\end{array}$} \\
\hline
\end{tabular}

\section{Curriculum Provision}

Based on the guidance of practical teaching, the cultivation mode, curriculum provision, content design, teaching model and evaluation methods in the current medical metrological education at academies were thoroughly demonstrated by referencing the standards and requirements of competency certification for medical metrologists and communicating with experts in National Medical Metrology Center. A brief introduction of the two medical metrological courses established from 2016 was shown in Table I. Moreover, the course assessment and examination were also strictly organized in accordance with teaching objectives and cultivation mode. The learning levels of theory course were assessed in a close-book written examination manner (without the use of the textbooks) by using the constructed item bank under the separation of teaching and testing. Additionally, students were randomly allocated in a double-blind pattern before examining their practice course via practical operation. The sheets of operational process and assessment score of each experimental item were 
normatively developed. The whole process of actual operation of students was examined on-site by teachers. After the assessment of two courses, the grades and performance of students were comprehensively reviewed. Students passes the examination were then awarded uniformed certifications of medical metrological verification officer authorized by the National Medical Metrology Center, which made it possible for students to be employed after graduation with the enhanced competency and qualification.

\section{E. Construction of Teaching Faculty}

The development of a strongly-cohesive medical metrological teaching team with complementary advantages and reasonable echelon structure is an important guarantee for promoting the establishment and reformation of the medical metrology curriculum and improving the teaching quality and effects. The following works were conducted to strengthen the construction of the teaching team.

\section{1) Faculty training}

Teachers were organized repeated study tours in National Institute of Metrology, Shaanxi Institute of Metrology, Military Medical Metrology Center, the first-class metrology station of PLA General Hospital, etc., which expanded the horizon and thinking ways of the faculty and intensified their cognition to medical metrology. Meanwhile, all teachers were organized to receive business training on newly-purchased metering equipment (e.g. Fluke and ALK Brand) and class observation given by top qualified teachers to improve their professional proficiency.

\section{2) Reasonable allocation}

The whole faculty was rationally allocated on the basis of curriculum content and their professional expertise. Each teacher has his/her own responsibility for the preparation of relevant teaching material.

\section{3) Post training}

The curriculum of medical metrology was established for the first time without previous experience for reference. Therefore, several teaching management methods (e.g. rehearsing or trail teaching, post training, collaborative lesson-planning, etc.) were utilized to guarantee the teaching quality and effects. The teaching design and teaching preparation were repeatedly deliberated to ensure the faculty qualification and curriculum quality.

4) Supervision and inspection

The whole teaching process was supervised by the head of department (via joining in each class) for the gatekeeping of teaching quality. Young teachers were especially instantaneously instructed after class. Additionally, the teaching process was also randomly supervised and inspected by the teaching supervision group of school and department.

\section{5) Student feedback}

The working attitude, professional capability and teaching quality of each teacher were laid follow-up investigation by conducting forum and questionnaire survey with students. The advice and suggestions were collected and feedback was then given to the teachers in time to facilitate improving the teaching profession.

\section{CURRICULUM IMPLEMENTATION AND REFLECTION}

Given the requirement of the curriculum construction and reformation, the brand-new education of medical metrology was implemented to the undergraduate students of the department of BME in our university on the basis of sufficient teaching argument and preparation from the fall quarter in 2016, which acquired satisfactory teaching effects. Students showed high learning enthusiasm on the highly-practical series courses of medical metrology evidenced by the active class atmosphere and initiative request for extra practice after class. All of the three sessions of undergraduate students have passed the course assessment and examination and obtained the qualification certificates of medical metrological verification officer authorized and awarded by the National Medical Metrology Center. The graduated students were all qualified for the measurement and detection of mass, pressure, electrophysiology, ultrasound, etc.

The two undergraduate courses of medical metrology were both established for the first time without former experience, which may induce some deficiencies and problems in the course preparation and practice process. Therefore, the opinions and suggestions from students were extensively solicited to understand their learning recept and also direct and amend the teaching process. On one hand, tutorial and question-answering sessions during the courses and periodical seminars were established. On the other hand, the feedback questionnaires were designed to collect students' suggestion, including curriculum provision, content arrangement, teaching methods, experience and feelings, question feedback, faculty evaluation, opinions and suggestions, etc. Statistical results of 49 valid questionnaires showed that both the necessity of the course establishment and the course satisfaction were $100 \%$, while the satisfaction of teaching quality was up to $93.8 \%$. The general opinions and suggestions of students were the increase of class hours and additional experimental subjects. All students thought that they have broadened their horizons and obtained substantial knowledge and techniques after receiving the medical metrological education, which was of vital significance for future study and work. The special symposium session was convened by the teaching group after each academic year to comprehensively summarize the annual teaching work and promote excellent experience and practices. Meanwhile, the existing problems were further analyzed and thought for the instruction and improvement of the teaching work next year.

The following aspects should be paid close attention in the later curriculum construction according to the results of teaching feedback.

Firstly, the knowledge cohesion should be focused on to avoid simple repetition. The medical metrology curriculum was scheduled at the first semester of the senior year when students have essentially completed professional basic courses and specialized courses and have erudite professional foundation knowledge. Therefore, the cohesion of knowledge structure should be paid close attention to avoid repeated education. For example, the cohesion with mathematical knowledge (e.g. probability and statistic) should be laid emphasis on in the education of data processing. Similarly, the cohesion with the medical equipment course should be specially emphasized in the theoretical teaching of specific verification items. 
Secondly, the experimental subjects should be increased to improve medical metrological ability of students. The results of questionnaires have demonstrated strong enthusiasm and desire for knowledge of students. The established subjects focused on the electrophysiology because of the period restriction. Therefore, the experimental subjects of medical metrological verification will be increased (e.g. biochemistry, radiology imaging) as wished based on the condition construction. Moreover, the high-level teaching subjects of traceability and calibration of the first-class medical metrology station will also be established.

Thirdly, the teaching methods should be enriched to improve the teaching efficiency. The student-centered PBL (Problem-Based Learning) education mode should be applied in the medical metrological teaching on the basis of constructivism theory. Students should be guided for positive thinking by the practical case analysis [11]. Meanwhile, the application of information-based teaching methods should also be enhanced to establish a virtual simulated experiment teaching platform to further improve the teaching efficiency [12].

\section{CONCLUSION}

After analyzing the requirement of talents' knowledge structure of medical metrology and the inner connection with the major the BME based on the current situation and problems of the medical metrological talents cultivation, we have found that it is of vital significance for undergraduate students in the colleges and universities to receive canonical and systematic quality-oriented education of medical metrology. With the connatural advantages in developing the medical metrology education, students majoring in BME should be the main force of medical metrology troops. After three-year construction and practice of the medical metrology curriculum, the talent cultivation mode of "basic knowledge + practical ability" was proposed and established aiming at improving the medical metrological ability of students of BME. Two undergraduate courses of medical metrology were explored and established for the first time on the basis of the gradual reformation and optimization of the establishment of textbooks, curriculum, teaching laboratory and teaching faculty. The new mode of the combination of course education and competency certification of medical metrology proposed in the article can improve students' competence in their medical metrology-related position, which can provide beneficial reference and assistance for colleges and universities to develop preferable cultivation of medical metrology talents.

\section{CONFLICT OF INTEREST}

The authors declare no conflict of interest.

\section{AUTHOR CONTRIBUTIONS}

Ze-Dong Yan, Wei Guo and Juan Liu conceived the curriculum construction; Er-Ping Luo and Chi Tang proposed the cultivating mode; Wei Guo, Er-Ping Luo and Chi Tang established the teaching laboratory; Ze-Dong Yan, Wei Guo, Juan Liu and Chi Tang compiled and published the textbooks; Ze-Dong Yan, Wei Guo, Juan Liu, Er-Ping Luo and Chi Tang contributed to the course provision; Ze-Dong Yan and Chi Tang wrote the paper; all authors had approved the final version.

\section{ACKNOWLEDGMENT}

This work was supported in part by the Medical Education Research Project of Medical Education Branch of Chinese Medical Association and Medical Education Professional Committee of Chinese Higher Education Society under Grant 2018B-N08046, in part by the Research Project on Teaching Reform of Education in Shaanxi Province under Grant 17BY134, and in part by the Teaching Reform Research Project of the Air Force Medical University under Grant CX201607.

We acknowledge the National Institute of Metrology, Shaanxi Institute of Metrology, Military Medical Metrology Center and the First Grade Metrology Station of PLA General Hospital for their technical assistance and collaboration in the construction of teaching laboratory and textbooks.

\section{REFERENCES}

[1] K. Li, M. Muhetebaier, J. W. Wang, S. M. Xie, K. Zhang, W. Tang, and F. Chen, "Medical legal dispute in hospitals of different grades: A retrospective study on 206 cases," Fa Yi Xue Za Zhi, vol. 30, no. 5, pp 355-356, Oct 2014.

[2] Z. Liu, Y. Zhan, J. O. Asante, Y. Huang, X. Wang, and L. Chen, "Characteristics of medical disputes arising from dental practice in Guangzhou, China: An observational study," BMJ Open, vol. 8, no. 2, p. e018738, Feb. 2018

[3] S. M. Ibrahim, P. Bills, and J. Allport, "Metrology education impediment - What do we need to do?" presented at the Academics World International Conference, Mecca, Saudi Arabia, Aug 23-24, 2017.

[4] B. G. Karaböce, M. Akgöz, H. Kaykısızlı, B. Yalçınkaya, and L. Dorosinskiy, "Medical metrology studies at Tübitak UME," in Proc. 17th International Congress of Metrology, 2015, p. 06011.

[5] J. Dobiliene and A. Meskuotiene, "Importance of education and competence maintenance in metrology field (measurement science)," Journal of Physics: Conference Series, vol. 588, no. 1, p. 012013 , 2015 .

[6] J. A. Baird, A. David, N. Therese, Hopfenbeck, and S. Gordon, "Metrology of education," Assessment in Education: Principles, Policy \& Practice, vol. 24, no. 3, p. 8, 2017.

[7] R. Magjarevic and D. M. Zequera, "Biomedical engineering education--status and perspectives," in 36th Annual International Conference of the IEEE Engineering in Medicine and Biology Society, IEEE, 2014, pp. 5149-5152.

[8] X. Y. Zhang, "Biomedical engineering for health research and development," European Review for Medical and Pharmacological Sciences, vol. 19, no. 2, pp. 220-224, May 2017.

[9] A. W. Eberhardt, O. L. Johnson, W. B. Kirkland, J. H. Dobbs, and L. G. Moradi, "Team-based development of medical devices: an engineering-business collaborative," Journal of Biomechanical Engineering, vol. 138, no. 7, pp. 0708031-0708035, June 2016.

[10] S. H. Zhong and W. L. Zhou, "Inquiry and experiential mixed teaching method is effective way to cultivate high-quality innovative talents," International Journal of Information and Education Technology, vol. 9, no. 9, pp. 613-617, 2019

[11] T. Yu, W. S. Ying, and K. Sha, "Explore the medical curriculum teaching development in the smart classroom," International Journal of Information and Education Technology, vol. 7, no. 2, pp. 130-134, 2017.

[12] L. Y. Lei and C. H. Wang, "strengthening scientific research ability of undergraduates, cultivating practical and innovative talents," International Journal of Information and Education Technology, vol. 3, no. 6, pp. 648-650, 2013

Copyright $(C) 2020$ by the authors. This is an open access article distributed under the Creative Commons Attribution License which permits unrestricted use, distribution, and reproduction in any medium, provided the original work is properly cited (CC BY 4.0). 


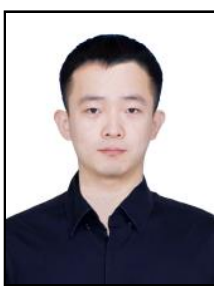

Ze-Dong Yan was born in Tengzhou, China, in 1992 $\mathrm{He}$ received the B.Eng. and M.Eng. degrees in biomedical engineering from Air Force Medical University, Xi'an, China, in 2015 and 2018, respectively.

$\mathrm{He}$ is currently a teaching assistant with the Department of Biomedical Engineering in Air Force Medical University. He has currently more than 10 publications and 3 computer software patents. His research interests include medical equipment development and medical metrology education.

Mr. Yan acts as a member of the Subcommission of Health Equipment Youth of Health Equipment Specialized Committee of Medical Science and Technology Committee of PLA. He has awarded the gold prize of Innovation and Entrepreneurship Competition of Science and Technology Workers of Shaanxi Province, the second prize in National Mathematical Modeling Competition.

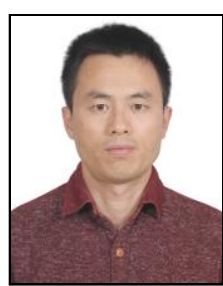

Wei Guo was born in Weinan, China, in 1982. He received the B.Eng., M.Eng., and Ph.D. degrees in Department of Instrument Science and Technology, School of Mechanical and Electrical Engineering and Automation, National University of Defense Technology, Changsha, China, in 2004, 2006, and 2011, respectively.

Since 2012, he has been appointed as a lecturer with the Department of Biomedical Engineering in Ai Force Medical University, China. He has more than 10 publications. His main interests are medical equipment and metrology.

Dr. Guo acts as a member of the Subcommission of Medical Metrology and Quality Control of Military Medical Engineering Committee. He is also the Member of the Subcommission of Medical Equipment Metrology of Health Equipment Specialized Committee of Medical Science and Technology Committee of PLA.

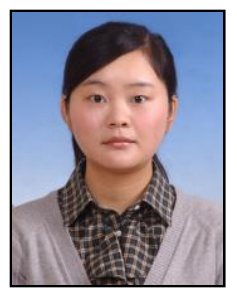

Juan Liu was born in Xi'an, China, in 1985. She received the B.B.M. degree in information management and system from Shaanxi Norma University, Xi'an, China, and M.M. degree in biomedical engineering from Air Force Medical University, Xi'an, China, in 2007 and 2015, respectively.

Since 2017, she has been acting as a teaching assistant with the Department of Biomedical Engineering in Air Force Medical University, China. In 2012, she was appointed to be the lecturer. She has more than 10 publications and 8 monograph books. Her main interests include new technology and equipment of oxygen production and supply, and medical metrology.

Ms. Liu is a member of the Subcommission of Medical Equipment Metrology of Health Equipment Specialized Committee of Medical Science and Technology Committee of PLA. She is also the member of the Subcommission of Medical Engineer Training and Education of National Medical Engineering Professional Committee.

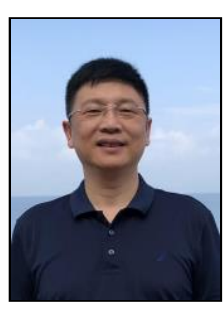

Er-Ping Luo was born in Chengdu, China, in 1959. He received the B.Eng. degree in aeronautical automation from Air Force Engineering University, Xi'an, China in 1982, and M.Eng. degree in theoretical electrical engineering from Hunan University, Changsha, China in 1986, and Ph.D. degree in electronic science and technology from Xidian University, Xi'an, China in 2005 .

He was appointed as a teaching assistant during 1982-1985 and a lecturer during 1986-1990 with the Teaching and Research Office Electrical Engineering in Air Force Engineering University, Xi'an, China. During 1990-1999, he was an associate professor with the Department of Biomedical Engineering in Air Force Medical University, China. He was then appointed as a full professor and the director of Teaching and Research Office of Military Medical Equipment and Metrology in the Department of Biomedical Engineering in Air Force Medical University during 1999-2002 and 2005-2019. He is currently a professor of the second grade. His research interests include medical equipment development, new technology of oxygen production and supply, and the mechanism of bone injury in extreme mechanical environment and the key preventive and therapeutic technology. Within these areas, he has (co)-authored more than 100 papers, obtained 25 national invention patents and 4 medical instrument registration certificates, and also published 12 monograph books. He has created the new pattern of academic education and post education in military medical equipment discipline.

Prof. Luo acts as the vice director of the Military Medical Engineering Committee, vice president of Medical Gas and Engineering Branch of National Industrial Gas Association, and Standing Member of Medical and Health System Engineering Committee of National Society of Systems Engineering. He has won the second prize of the National Science and Technology Progress Award, and 2 second prizes of Military Science and Technology Progress Award. Prof. Luo also received the gold award of Talent Cultivation of Military Academy.

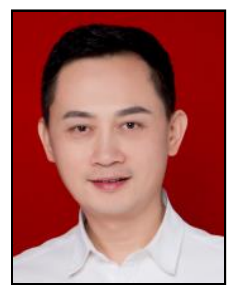

Chi Tang was born in Qiqihar, China, in 1977. He received the B.Eng., M.Eng., and Ph.D. degrees in Department of Biomedical Engineering from Air Force Medical University, Xi'an, China, in 2000, 2005, and 2008, respectively.

Since 2013, he has been acting as an associate professor with the Department of Biomedical Engineering in Air Force Medical University, China. In 2011, he has been appointed as a master supervisor. In 2019, he was nominated to be the director of Teaching and Research Office of Military Medical Equipment and Metrology in the Department of Biomedical Engineering in Air Force Medical University, China. He has more than 60 publications, obtained 18 national invention patents and 2 medical instrument registration certificates, and also published 8 monograph books. His main interests are medical equipment and medical metrology education. He firstly explored and established undergraduate courses of medical metrology, and created a new mode of the combination of course education and competency certification of medical metrology.

Prof. Tang is a standing committee member of the Subcommission of Medical Metrology of National Metrological Measuring Institute. He also acts as the vice chairman of Subcommission of Equipment Metrology of Military Medical Equipment Specialized Committee. Prof. Tang also awarded the First Prize of Science and Technology of Shaanxi Province. 